\title{
An fMRI study on the influence of sommeliers' expertise on the integration of flavor
}

\author{
Lionel Pazart ${ }^{1 *+}$, Alexandre Comte ${ }^{1,2,3+}$, Eloi Magnin ${ }^{2,3}$, Jean-Louis Millot ${ }^{2}$ and Thierry Moulin ${ }^{1,2,3}$ \\ ${ }^{1}$ Inserm Clinical Investigation Centre 1431, Clinical Investigation Centre, Besançon University Hospital, Besancon, France \\ 2 Laboratoire de Neurosciences, (EA-481), University of Franche-Comté, Besancon, France \\ ${ }^{3}$ Département de Recherche en Imagerie Fonctionnelle, Besançon University Hospital, Besancon, France
}

\section{Edited by:}

Donald A. Wilson, New York

University School of Medicine, USA

Reviewed by:

Daniel W. Wesson, Case Western

Reserve University, USA

Wen Li, University of

Wisconsin-Madison, USA

*Correspondence:

Lionel Pazart, Inserm Clinical

Investigation Centre 1431,

Besançon University Hospital, 2

Place St Jacques,

25030 Besancon, France

e-mail: Ipazart@chu-besancon.fr

t'These authors have contributed equally to this work.
Flavors guide consumers' choice of foodstuffs, preferring those that they like and meet their needs, and dismissing those for which they have a conditioned aversion. Flavor affects the learning and consumption of foods and drinks; what is already well-known is favored and what is new is apprehended. The flavor of foodstuffs is also crucial in explaining some eating behaviors such as overconsumption. The "blind" taste test of wine is a good model for assessing the ability of people to convert mouth feelings into flavor. To determine the relative importance of memory and sensory capabilities, we present the results of an fMRI neuro-imaging study involving 10 experts and 10 matched control subjects using wine as a stimulus in a blind taste test, focusing primarily on the assessment of flavor integration. The results revealed activations in the brain areas involved in sensory integration, both in experts and control subjects (insula, frontal operculum, orbitofrontal cortex, amygdala). However, experts were mainly characterized by a more immediate and targeted sensory reaction to wine stimulation with an economic mechanism reducing effort than control subjects. Wine experts showed brainstem and left-hemispheric activations in the hippocampal and parahippocampal formations and the temporal pole, whereas control subjects showed activations in different associative cortices, predominantly in the right hemisphere. These results also confirm that wine experts work simultaneously on sensory quality assessment and on label recognition of wine.

Keywords: fMRI, flavor, expertise, wine, olfaction pathways, taste

\section{INTRODUCTION}

Flavor is a crucial subject of study for understanding eating behavior, for the prevention of obesity, overdrinking and other eating disorders, and for the foods and drinks industry. The cortical integration of olfactory and gustatory information could modulate mechanisms involved in food selection and emotional reactions relating to the chemical senses (Fu et al., 2004). Flavor of foodstuffs refers to this combination of sensations perceived inside the mouth, combining taste (savor) and smells (aromas), as well as trigeminal somatosensory perception and thermal perception (Auvray and Spence, 2008; Prescott, 2012). Several previous neuroimaging studies analyzed brain regions activated by intrinsic cues of flavor (Cerf-Ducastel and Murphy, 2001; O'Doherty et al., 2001; Kobayashi et al., 2004; Kikuchi et al., 2005; Boyle et al., $2007 \mathrm{a}, \mathrm{b})$ and the convergence of taste and retronasal olfaction was mainly elicited the anterior part of the orbitofrontal cortex (de Araujo et al., 2003; Small et al., 2004; Small and Prescott, 2005). More precisely, flavor integration following retronasal stimulation may involve brain structures like the insula, the frontal operculum and the caudal orbitofrontal cortex (OFC) (Cerf-Ducastel and Murphy, 2001; de Araujo et al., 2003; Small et al., 2004; Small and Prescott, 2005) but also the amygdala, and cerebellum (Cerf-Ducastel and Murphy, 2001).
Other neuroimaging studies confirmed the high effects on taste and flavor perception by different extrinsic cues such as the appearance of the foodstuff, packaging design, brand name, geographical origin, price, subjective flavor preferences (McClure et al., 2004; Plassmann et al., 2008; Kühn and Gallinat, 2013; Okamoto and Dan, 2013; Van den Bosch et al., 2014) and also the simple evocation of the odor or product name (Royet et al., 2013a; Bensafi et al., 2014).

One main factor that might influence the effect of either intrinsic or extrinsic cues could be the strength of the taste/flavor memory associated with the cue (Okamoto and Dan, 2013). Indeed, the extraordinary performance of experts in many matters (chess, bridge, music, wine etc.) raises the question of the origin of their faculties. It is often found that experts and novices use different criteria to categorize domain-specific problems, in that novices use simplistic surface features whereas experts use underlying principles (Vicente and Wang, 1998).

Wine expertise provides an interesting field in which to test theories of skill acquisition since it is generally believed to be based mainly on advanced perceptual skills rather than cognitive ones, such as categorical knowledge or episodic memory (Hughson and Boakes, 2002; Saive et al., 2014). Perceived quality of a wine is dependent on consumers' level of expertise 
(Sáenz-Navajas et al., 2013). Experience tends to generate idiotypic recollections, to which new wines are compared (Hughson and Boakes, 2002). Accordingly, odor experts who are trained daily can acquire better olfactory sensitivity, and thus olfactory mental imagery capacities develop with practice and do not result from innate skill (Plailly et al., 2012). During the creation of mental images of odors, expertise influences not only the primary olfactory area (piriform cortex) but also the OFC and the hippocampus, regions that are involved in memory and the formation of complex sensory associations, respectively (Royet et al., 2013b; Saive et al., 2014). In these areas, the magnitude of activation was negatively correlated with experience: the greater the level of expertise, the lower the activation of these key regions (Royet et al., 2013b). Nevertheless, in wine expertise several behavioral studies (Brochet and Dubourdieu, 2001; Morrot et al., 2001; Hughson and Boakes, 2002; Parr et al., 2002; Ballester et al., 2008; Brand and Brisson, 2012) have compared wine experts and novices, and surprisingly no difference in olfactory sensitivity was revealed between them. This discrepancy between odor experts and wine experts could be explained by the needed integration of several sensory modalities for wine: sight, orthonasal olfaction, somesthesia, and chemical senses including trigeminal sensitivity, taste, and retronasal olfaction (Brochet and Dubourdieu, 2001; Morrot et al., 2001). Parr et al. (2002) demonstrated that wine experts have similar sensitivity for wine-related components such as tannin or alcohol, and similar odorant naming abilities compared to those of wine novices but superior explicit identification and memory recognition for wine-relevant odorants. For some authors, this greater ability of wine experts to recognize and identify odors is probably due to better semantic knowledge (Hughson and Boakes, 2002), however this remains an open question (Parr et al., 2004; Ballester et al., 2008). In this way, in addition to the structures involved in taste and retro-olfaction, those mechanisms might involve in wine experts a predominance of the left hemisphere, involved in analytic and linguistic treatment, and probably the temporal lobes and hippocampus, involved in episodic and semantic memory, related to previous experiences. In contrast, Parr et al. demonstrated the importance of perceptual skill, namely sensory memory for odorant and trigeminal perception, rather than semantic memory ability, in wine-relevant olfactory expertise (Parr et al., 2004).

To determine the relative importance of different types of memory and sensory capabilities in wine expertise, few studies have been performed with neuroimaging techniques and until present Castriota-Scanderbeg's study might be the only study involving wine experts and novices (Castriota-Scanderbeg et al., 2005).

Castriota-Scanderbeg's study compared via fMRI the brain activations of two groups of 7 wine experts (sommeliers) and 7 novices who received randomly $2 \mathrm{ml}$ bolus of 3 Italian wine or glucose solution via a multi-channel device inserted in the mouth. Sommeliers showed greater activity in the left insula and orbitofrontal cortex than the novices. The principal areas activated in the novices were the primary gustatory cortex and the regions associated with emotional processing (CastriotaScanderbeg et al., 2005). This study confirmed the involvement of olfactory memory in wine assessment by wine professionals.
However, the primary olfactory area (piriform cortex) was not activated either in wine experts or novices, and surprisingly no activation occurred between the wine and glucose solution in mouth, i.e., during "taste phase." Significant differences were observed only after swallowing a bolus, i.e., during the after-taste phase. Thus, the integration of flavor seems to be delayed contrary to what is usually observed by sommeliers and reserved to expert unlikely results of behavioral experiments.

Our hypothesis is that a specific effect of expertise may be observed early during the taste phase anticipating the after-taste phase, and requiring flavor memory and episodic memory rather than semantic memory. Therefore, we would like to replicate Castriota-Scanderbeg's study with a tasteless comparator to avoid the possible overshadowed effect of glucose solution on the taste part of brain activation. Thus, our study objective was to evaluate brain activity with fMRI during the taste and after-taste phases of wine tasting vs. a tasteless water comparator directly delivered into the mouth of a sample of matched-pair experts and novices tasters in order to determine the relative importance of memory and sensory capacities in wine flavor integration.

\section{MATERIALS AND METHODS SUBJECTS}

We recruited 20 subjects, 10 famous sommeliers (seven men and three women) from France and Switzerland and 10 matched controls. All sommeliers had been active professionals for at least 5 years. Most had received awards such as "Best sommelier in the world," "Best sommelier in Europe," "Best sommelier in France," or "Best sommelier in Switzerland" and were working in prestigious restaurants in either France or Switzerland. Each sommelier was matched with a control subject of the same sex and same age ( \pm 5 years) because chemosensory abilities can vary with gender and age (Doty, 1989; Yousem et al., 1999; Brand and Millot, 2001; Wang et al., 2005; Lundstrom and Hummel, 2006). Subjects were all aged between 24 and 67 years. In addition, the control subjects were from the same region as their matched expert in order to limit bias induced by the difference of regional flavor habits in each pair. All subjects were right-handed and nonsmokers, as smoking habits can also influence sensory abilities (Katotomichelakis et al., 2007). All subjects underwent a medical examination to screen for MRI contra-indication and for any possible gustatory or olfactory dysfunctions before the study. The protocol was approved by the local ethics committee (Comité de Protection des Personnes CPP Est II) and declared to the national authority ( $\mathrm{N}^{\circ}$ UF: 1013; DGS 2006/0494). Written informed consent was obtained from all participants.

\section{CHOICE OF STIMULI AND STIMULUS DELIVERY}

Two wines (one white chardonnay variety, Arbois 2004, and one red "black pinot" variety, Côte du Jura 2006) were chosen for their good sensorial qualities from an expert point of view by an experienced sommelier (C. Menozzi) who was not participating in the study. He also tasted different types of water (including distilled water and physiologic serum) and deemed the local water to be the most suitable for control (in terms of salinity, tastelessness, and low minerality) and rinsing. A multi-channel custom-built gustometer was used to deliver the wine and water to the subjects 
(Andrieu et al., 2014). This device comprises three reservoirs, one for each type of liquid, and a computer-controlled pneumatic distributor, which dispatches air toward several exits. Each reservoir has its own opaque polythene tube, which transports the liquid toward the subject's mouth. The bolus was delivered in two stages: (1) the pneumatic distributor injected air into the appropriate reservoir in order to push the required volume of liquid into the tube; (2) air was injected into the connected tube, pushing the liquid into the subject's mouth. The bolus $(2 \pm 0.11 \mathrm{ml})$ was delivered in $0.34 \pm 0.06 \mathrm{~s}$. The three tubes were contained within a larger silicon tube ( $10 \mathrm{~mm}$ exterior diameter). Consequently, the subject only felt one tube in their mouth and was unable to see which liquid was being delivered.

Before undergoing MRI, each participant tested the device used for the administration of wine samples with the reference solution ( $2 \mathrm{ml}$ samples of water) to familiarize him or herself with the experimental tasting procedure. This involved lying in a horizontal position and limiting any lip or jaw movements. Subjects were asked to swish water in their mouths, just as they were required to do with wine or water during the scan session. The same paradigm was used for the acquisition of images.

\section{EXPERIMENTAL PROTOCOL}

To avoid confusion between "taste as in common usage," and "taste as a unimodal sensation," hereafter we will follow the convention in chemosensory studies where "taste" refers to a unimodal sensation.

During the first phase (taste), subjects had to swish either wine or water (bolus of $2 \mathrm{ml}$ ) in their mouth for $7 \mathrm{~s}$. At the end of the taste phase, an auditory cue prompted the tasters to swallow the liquid, signaling the beginning of the second phase (after-taste), which lasted $13 \mathrm{~s}$. Each $2 \mathrm{ml}$ bolus of wine was repeated twice before rinsing. There was a rest period of $15 \mathrm{~s}$ after each rinsing, resulting in a block of 1 min $15 \mathrm{~s}([7+13 \mathrm{~s}] \times 3+15 \mathrm{~s})$. Each subject performed five blocks. The durations of the taste and after-taste periods were the same as in a previously validated study (Castriota-Scanderbeg et al., 2005). During the scan, subjects were asked to keep their eyes closed. Participants received no information on the number of wines chosen or their characteristics. In addition, the order in which the red and white wines were delivered was randomized according to test at least once each variety of wine and was therefore unknown to the subjects.

\section{MRI DATA ACQUISITION}

The functional MRI study was performed on a 3-Tesla (GE Healthcare Signa HDxt, Milwaukee, WI) MR system with a standard $40 \mathrm{mT} / \mathrm{m}$ gradient using blood-oxygen level-dependent (BOLD) fMRI. Foam cushions were used to minimize head movements within the coil. The experiment began with the acquisition of a high-resolution, T1-weighted, 3-dimensional anatomical scan (BRAVO sequence). This scan was acquired in 134 slices with $0.47 \times 0.47 \times 1.2 \mathrm{~mm}$ resolution. Functional images were then obtained parallel to the anterior-posterior commissure line, covering the entire cerebrum (30 slices) using an echo planar imaging (EPI) sequence $($ slice thickness $=4.5 \mathrm{~mm} ; T R=2500 \mathrm{~ms} ; T E=$ $35 \mathrm{~ms}$, matrix $=128 \times 128 ; \mathrm{FoV}=256 \mathrm{~mm}$; Flip Angle $=90^{\circ}$; phase acceleration factor $=2$; auto-shimming).

\section{fMRI DATA ANALYSIS}

Image time-series analysis was performed using BrainVoyager QX 2.1 (Brain Innovation, Maastricht, The Netherlands). The time-series were corrected for slice acquisition time, realigned with their corresponding T1 volumes, warped into standard space (Talairach and Tournoux, 1988), re-sampled into $2 \mathrm{~mm}$ isotropic voxels, motion-corrected using Levenberg-Marquarts's least square fit for six spatial parameters, highpass-filtered for removal of low frequency drifts, corrected voxel-wise for linear drifts, and spatially smoothed using a 5-mm full-width at half-maximum Gaussian kernel.

The general linear model (GLM) was computed from the 20 z-normalized volume time courses. For all stimuli of interest, i.e., rest period, taste period and after-taste period, box-car time courses with a value of 1 for the stimuli of interest and values of 0 for the remaining time points were convolved with a theoretical hemodynamic response function (Boynton et al., 1996) and were entered as predictors into the design matrix of the study. Contrast analyses were based on random effects GLMs of the z-normalized volume time courses.

Analyses of the taste and after-taste periods were firstly performed for the entire group (20 subjects) using a statistical threshold of $q(\mathrm{FDR})<0.01$ corrected for multiple comparisons. A minimum cluster size of $48 \mathrm{~mm}^{3}$ was set. As suggested by Zald and Pardo (2000) for controlling in-mouth non-gustatory factors, we considered the water after swallowing period as a reference for the contrasts of wine vs. water for both periods.

The same analyses were then performed for each group separately (experts and controls). As the number of subjects in each sub-group is half the entire group, another statistic was chosen.

A cluster size threshold yielding the equivalent of a whole-brain corrected for a multiple comparison significance level of $P<0.05$ was used after voxel-wise thresholding at $P<0.005$ (uncorrected). The BrainVoyager Cluster-Level Statistical Threshold Estimator plug-in estimating the overall significance level by determining the probability of false detection through Monte Carlo simulation was used (with 10,000 Monte Carlo iterations).

Finally, for both the taste and after-taste periods, a group comparison was carried out to identify the brain areas affected by the level of expertise in wine appreciation and perception. A statistical extent threshold of $P<0.05$ corrected for multiple comparisons after a voxel-wise thresholding at $P<0.005$ was used.

\section{RESULTS}

Table 1 shows the cerebral activations for the whole sample of subjects (experts and controls) obtained for the contrast "wine minus water" during taste phase and after-taste phase. During the taste phase, activations were found in the insula, the frontal lobe (bilateral motor area and right superior and dorso-lateral prefrontal cortex), pallidum, left parahippocampic gyrus and left thalamus. During the after-taste phase, activations were again present in the insula and in various areas of the frontal lobe including the orbito-frontal cortex.

When considering experts and controls separately, the same contrasts revealed that certain activations were specific to one group of subjects in both the taste and the after-taste periods 
Table 1 | Wine minus water contrast for all subjects (simple main effects).

\begin{tabular}{|c|c|c|c|c|c|c|}
\hline & Activation locus & $\boldsymbol{x}$ & $y$ & $z$ & Max $t$-value & $\kappa$ \\
\hline $\mathrm{L}$ & Pars opercularis & -55 & 2 & 8 & 6.08 & 555 \\
\hline $\mathrm{R}$ & Middle frontal gyrus & 49 & -56 & -3 & 4.85 & 120 \\
\hline L & Superior frontal gyrus (supplementary motor area) & -5 & -10 & 57 & 7.36 & 2045 \\
\hline $\mathrm{R}$ & Superior frontal gyrus (supplementary motor area) & 3 & -4 & 56 & 7.69 & 2119 \\
\hline L & Precentral gyrus & -54 & -15 & 34 & 9.31 & 1567 \\
\hline $\mathrm{R}$ & Postcentral gyrus & 54 & -25 & 27 & 8.21 & 203 \\
\hline $\mathrm{R}$ & Inferior temporal gyrus & 54 & -58 & -23 & 6.01 & 622 \\
\hline L & Parahippocampal gyrus & -14 & -29 & -8 & 4.31 & 21 \\
\hline $\mathrm{L}$ & Superior temporal gyrus & -58 & -19 & 10 & 5.96 & 1716 \\
\hline $\mathrm{R}$ & Superior parietal lobule & 30 & -56 & 48 & 5.51 & 1237 \\
\hline $\mathrm{R}$ & Cerebellum & 32 & -48 & -38 & 5.75 & 414 \\
\hline $\mathrm{R}$ & Cerebellum & 29 & -54 & -23 & 5.25 & 416 \\
\hline $\mathrm{R}$ & Cerebellum & 18 & -62 & -20 & 6.71 & 578 \\
\hline $\mathrm{R}$ & Cerebellum & 4 & -82 & -21 & 5.56 & 508 \\
\hline L & Cerebellum & -29 & -53 & -39 & 4.96 & 241 \\
\hline L & Cerebellum & -18 & -64 & -21 & 5.07 & 592 \\
\hline L & Cerebellum & -43 & -48 & -28 & 5.44 & 797 \\
\hline L & Globus pallidus & -26 & -5 & -2 & 7.17 & 213 \\
\hline $\mathrm{R}$ & Globus pallidus & 21 & -4 & -4 & 5.87 & 442 \\
\hline L & Superior frontal gyrus (supplementary motor area) & -2 & 12 & 56 & 7.71 & 777 \\
\hline L & Superior frontal gyrus (supplementary motor area) & -5 & 23 & 40 & 6.73 & 901 \\
\hline L & Anterior insula & -47 & 18 & -3 & 5.91 & 178 \\
\hline L & Anterior insula & -33 & 21 & 1 & 5.97 & 250 \\
\hline
\end{tabular}

Cerebral activations for the whole sample of subjects (experts and controls) obtained for the contrast "wine minus water" during the taste and after-taste phases

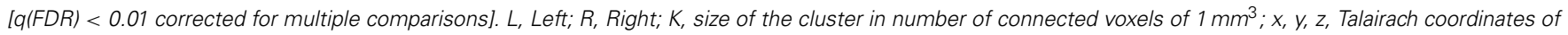
the maximum peak.

(Table 2). Consequently, further analyses focused on the contrasts between experts and controls during the wine taste phase and the wine after-taste phase, which was the aim of the study.

Table 3A shows the activated regions when contrasting experts and control subjects during the wine taste phase. When contrasting experts minus control subjects, activations were observed in the brainstem (left bulbo-pontic junction extended to left trigeminal nucleus), the cerebellum and subcortical areas (locus niger, globus pallidus). Cortical activations were present in the hippocampi, parahippocampal gyri, amygdalae, periamygdal cortex (entorhinal and perirhinal cortex), temporal and occipital lobes and in the right anterior insula. There were more widespread bilateral activations of the parietal lobes in control subjects compared to experts. During the wine taste phase, control subjects activated 18 regions vs. 9 for experts.

Table 3B shows the activated regions when contrasting experts and control subjects during the wine after-taste phase. Experts exhibited fewer cerebral activations (in terms of number and size of clusters) compared to controls. These activations involved the right temporal lobe and left hippocampus. In the reverse contrast (control subjects minus experts), activations involved the frontal, temporal and parietal (postcentral gyrus) cortices and the anterior insula. Subcortical activations were restricted to the caudate nucleus. 


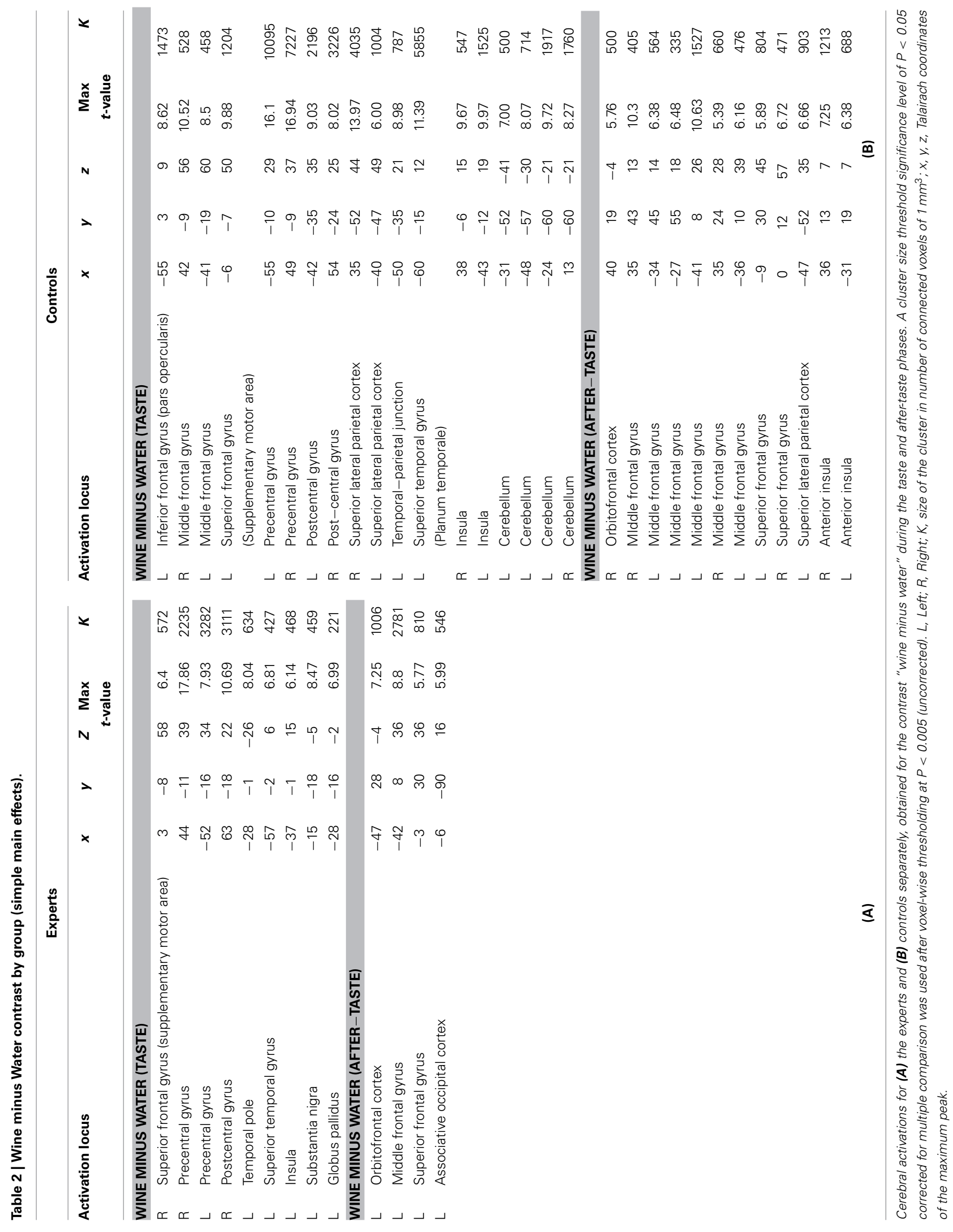




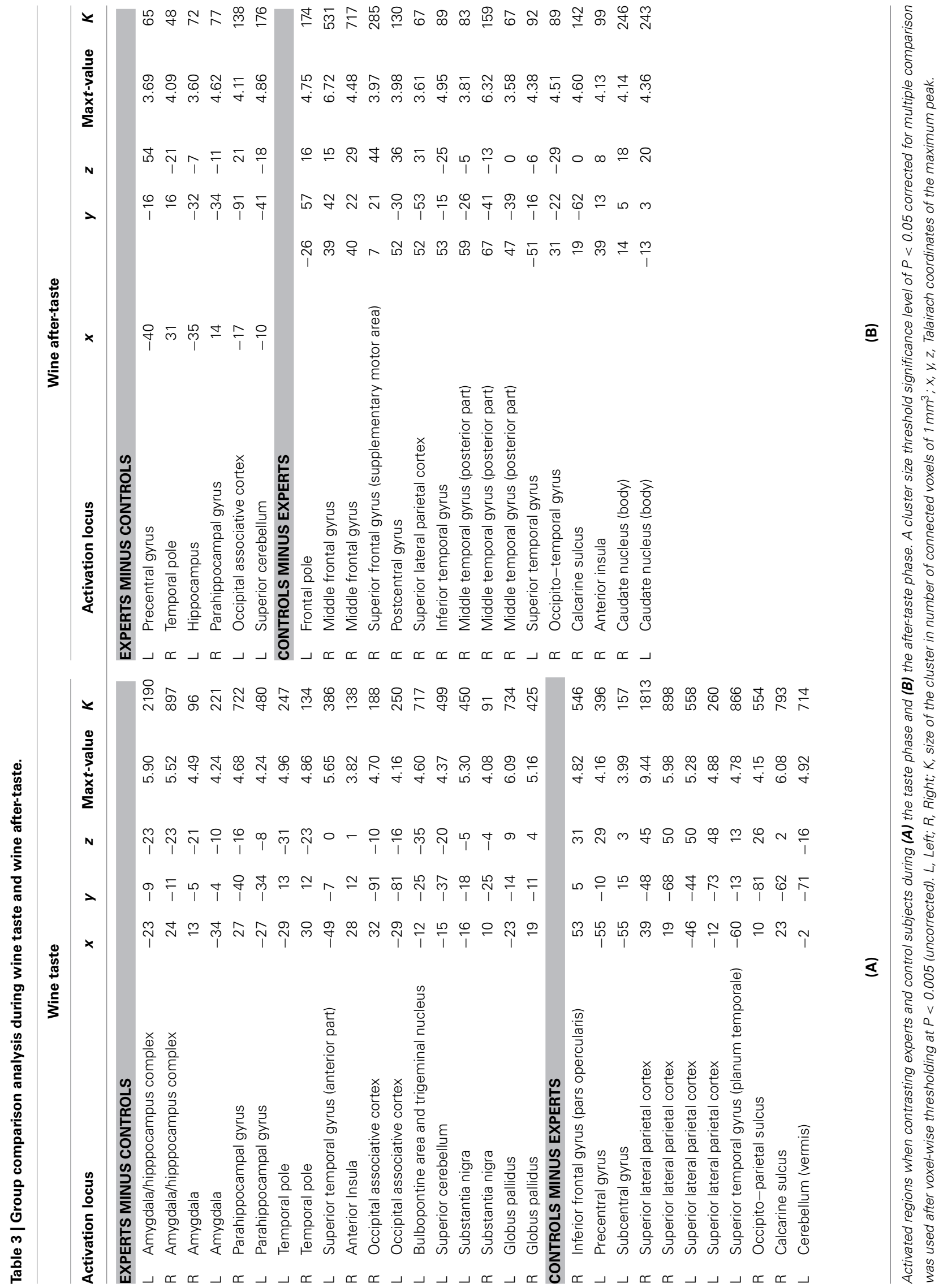




\section{DISCUSSION}

This study was designed to describe the differences in brain activity in wine experts compared to control subjects, especially during wine tasting as stimuli compared to water, in order to confirm the influence of expertise on flavor integration. In addition, we would like to identify the type of memory used by experts in order to demonstrate experts requiring flavor memory and episodic memory rather than semantic memory. As expected, we observed specific areas activated in the experts' brains during all phases of wine tasting. Structures involved in the sensory and cognitive tasks of the expertise-related process were activated either during the taste phase, corresponding to gustatory and trigeminal sensations, and the after-taste phase, corresponding to retroolfactory sensation. In addition, an unexpected and interesting result during the taste phase was that specific brainstem activation was observed in the expert group, suggesting that expertise can modify sensory treatment in addition to cortical cognitive processes.

\section{ABILITY OF THE PARADIGM TO FOCUS ON FLAVOR Choice of reference stimulus}

Direct comparison between our results and those from the only neuroimaging study on wine experts vs. novices, by Castriota-Scanderbeg et al. (2005), should be interpreted with caution because of the difference of wines and reference stimulus in both studies. Instead of using glucose as the reference stimulus, we chose neutral water as the reference stimulus used currently in neuroimaging (Zald and Pardo, 2000) and wine behavioral experiments. The authors of this previous study argued their choice in order to adequately control the sweet components of the gustatory stimulus (but only one of their three tested wines was sweet) and to avoid somatosensory and motor components of the task (Castriota-Scanderbeg et al., 2005). Accordingly, the use of a glucose drink as reference stimulus might have overshadowed the taste part of brain activation while a sweet drink might present similar taste and trigeminal characteristics as tested wines. Furthermore, there is a great consumer preference for sweet wines in many countries and wine experts seem to prefer wines with less added glucose than the novices (Blackman et al., 2010). Sweet drinks might therefore appear more "pleasant" for novices than for experts and introduce another bias since a subjectively pleasant stimulus would have preferentially activated the medial OFC whereas an unpleasant stimulus would have preferentially activated the lateral OFC (Rolls et al., 2003). Moreover, comparing activations in response to a sweet solution or a bitter solution, tasting sweet solution caused greater activations in the OFC whereas tasting a bitter solution resulted in greater activations in the cingulate cortex, operculum and precentral gyrus (Van den Bosch et al., 2014). So in order to minimize bias, we chose exclusively dry wines for stimuli and a tasteless and odorless comparator (neutral water).

\section{Isolation of in-mouth stimulation}

We replicated the design of Castriota-Scanderbeg's study (Castriota-Scanderbeg et al., 2005) using a multi-channel custom-built gustometer to deliver the wine or comparator directly into subjects' mouths, with identical volume $(2 \mathrm{ml})$ and duration of bolus stimuli, the same frame of run and similar fMRI analysis. This design tries to isolate the influence of inmouth sensations on the flavor integration without orthonasal olfactory stimulation or external cues. Similar designs have been adopted in numerous neuroimaging studies on gustation (Kühn and Gallinat, 2013; Van den Bosch et al., 2014) despite wellknown bias due to the supine conditions of the experiment, the lowering perceived intensity functions for taste stimuli affected by the stimulus delivery technique in the MRI scanner (Haase et al., 2009) and by the small amount of stimulus (2 vs. 5-20 ml for sip and spit techniques of behavioral experiments).

In the case of gustatory stimulation, we cannot exclude the possible contribution of other factors, since intraoral stimuli involve several types of processing in addition to gustation: olfaction, somatosensation, and oral movements. This complex interaction makes it difficult to identify the brain regions selectively processing gustation (Kobayashi, 2006).

Rozin (1982) first suggested that olfaction is a dual sense modality because it contributes to the perception of external and internal substances (via orthonasal and retronasal olfaction, respectively). Orthonasal perception can identify objects at a distance, and retronasal perception contributes to flavor and hence food identification in the mouth. These two "olfactory senses" differ physiologically in terms of delivery of odors to the olfactory epithelium (Pierce and Halpern, 1996), but also in terms of connections between senses and cognitive impact. Small and Prescott (2005) have demonstrated that routes of delivery produced differential activations in the insula/operculum, amygdala, thalamus, hippocampus, and caudolateral orbitofrontal cortex in orthonasal $>$ retronasal and in the perigenual cingulate and medial orbitofrontal cortex in retronasal $>$ orthonasal in response to chocolate, but not lavender, butanol, or farnesol, so that an interaction of route and odorant may be inferred. These findings demonstrate differential neural recruitment depending upon the route of odorant administration (orthonasal or retronasal) and suggest that its effect is influenced by whether an odorant represents a food or not (Small and Prescott, 2005). Small and Prescott (2005) explain these observations by the fact that taste perception is almost always accompanied by olfactory and oral somatosensory perception in the context of eating, whereas olfaction often occurs separately outside the context of eating. Thus, it would appear logical, in the identification of food in the mouth, to combine the food's qualities (savor, palatability and aromas) into a unitary perception (Prescott, 1999). Wine tasting in the mouth typically involves simultaneous gustatory, trigeminal and retro-olfactory information (Brochet and Dubourdieu, 2001). Wine could be a very good model to test the ability of people to perform this convergence of sensorial information in flavor integration. Like Castriota-Scanderbeg, we adopt the terminology of "taste phase" and "after-taste phase" to indicate the period before and after swallowing instead of dissociating responses to taste and smell stimuli. An issue is the succession of both phases (taste and after-taste). In this experiment (and in every experiment studying these two distinct periods) it is unavoidable that both phases are consecutive. In fact, flavor compounds are progressively released from the wine during the mouth process before swallowing particularly with the impregnation by saliva (Salles 
et al., 2011). So, even if the main perception during the taste phase remains from the gustation and trigeminal stimulation, there is an overlapping with the beginning of retronasal olfaction stimulation. Secondly, mouth movements and swallowing play a role in the enhancement of retronasal odor perception analogous to that played by sniffing in orthonasal perception (Burdach and Doty, 1987). This may lead to a diminishing of observed effects during the after-taste phase due to retro-nasal stimulation (even weak) during the taste phase, and due to memory processes (particularly with experts). Accordingly, the after-taste phase corresponds mainly to retronasal olfactory stimulation with a residual part of the preceding taste stimuli. In addition the $7 \mathrm{~s}$ taste phase duration may also lead to the situation where a slow response to the first process can fall into the time window of the after-taste phase and be interpreted as reflecting this second process. However, there is little chance that areas of interest (that is, those involved in olfaction, gustation and memory), if recruited during the taste phase, start to be active only during the after-taste phase. As such, responses even time-locked to the two events are still convoluted. One has then to keep in mind this issue when interpreting results with such paradigms.

In order to secure the exclusivity of in-mouth stimulation, no information was given about the color, types or number of wine since exposure to visual or verbal semantic odor/taste information alone could activate the piriform cortex, the amygdala or the insula (Kobayashi et al., 2004; González et al., 2006; Bensafi et al., 2014).

Nevertheless, wine tasting typically involves three phases contributing to a final synthesis of flavor analysis: firstly, wine tasters normally appreciate the sight of the wine and mainly the color, activating occipital visual areas, secondly they sniff the wine and orthonasal olfaction impacts on gustation and olfactory areas, finally they absorb a small amount of wine in their mouth, trill the wine, aerating it and allowing the flavors to be perceived by retroolfaction before being spat. In our design, we shunted sight and ortho-nasal olfaction and so flavor integration is not complete.

\section{SENSORY/FLAVOR INTEGRATION \\ Taste phase and in-mouth sensations}

The main difference between our results and CastriotaScanderbeg's study is the presence of taste phase activations, especially brain stem responses which suggest that expertise also impacts on basic taste processing. The modification of the paradigm by using water as a control explores this part of flavor processing that was possibly overshadowed by glucose control in Castriota-Scanderbeg's study, as previously explained.

Although no significant differences emerged between wine and glucose either in controls or in sommeliers during the taste period in Castriota-Scanderbeg's study, we found significant cerebral activations in the insula, frontal lobe (bilateral motor area and right superior and dorso-lateral prefrontal cortex), cerebellum, pallidum, left parahippocampic gyrus and left thalamus for the whole sample of subjects (Table 1) obtained for the contrast "wine minus water" during taste phase. These regions correspond to an area commonly activated by gustatory stimulation (Kobayashi, 2006): the superior frontal, middle frontal, inferior frontal, precentral, and postcentral gyri, insula/frontal operculum, inferior parietal lobe, and cerebellum and in addition to these regions, the thalamus and the region including the putamen.

Our study showed that the volume of activated regions in the insula/frontal operculum during gustatory stimulation was higher in the left hemisphere than in the right. Although most neuroimaging studies have shown that the right insula is more intensively activated than the left (Cerf-Ducastel and Murphy, 2001; Small and Prescott, 2005; Kobayashi, 2006) some studies have shown that activation in the left insula could be equal to or more dominant than the right insula (Kinomura et al., 1994; Francis et al., 1999).

There is no activation of the OFC during the taste phase either for experts or novices (Table 2), but a passive gustatory stimulus may not always be sufficient to activate the region (Kobayashi et al., 2004).

When considering the wines as stimuli and comparing experts to control subjects (experts minus control subjects, Table 3), there appeared to be involvement of the bulbo-pontic junction and trigeminal nuclei in the brainstem, suggesting specific chemosensory information processing in experts than controls. Motor activity induced by swallowing may have engaged brainstem activation. However, both groups had to swish and swallow the bolus of wine and no activations were found in the motor cortical area for this contrast. Although rarely mentioned, this result highlights the importance of trigeminal sensitivity in addition to gustatory perception in wine analysis. Indeed, several descriptors used in wine tasting (such as astringent, bitter, spicy, sharp or sweet) are typically trigeminal-type descriptors (Laska et al., 1997). Trigeminal activations were not mentioned by CastriotaScanderbeg et al. (2005), which may have been due to the sweet type of reference stimuli and one of the three tested wines. It is somewhat surprising to find different sensory processing in experts compared to controls in this first stage of brainstem integration of the stimuli.

Activity was observed in the amygdala, enthorhinal and perirhinal cortices and anterior insula. Activation of the anterior insula is congruent with the taste phase as this area is involved in the integration of multimodal input such as olfactory (Sobel et al., 2003), gustatory (Small et al., 1997, 1999) and trigeminal (Lombion et al., 2009) stimuli. Its role in the hedonic evaluation of chemosensory stimulations (Fulbright et al., 1998; Small et al., 2001) and discrimination processes (Bengtsson et al., 2001) has also been suggested. Activity in the amygdala may have corresponded to the selective perception of olfactory stimuli via the retronasal pathway which started in experts before swallowing, since its activation strongly characterizes olfactory processes (Zatorre et al., 1992; Sobel et al., 2003). Moreover, psychophysical investigations in humans and behavioral work in animals have shown that the taste system plays an integral role in odor processing. While there is evidence to support the anticipation of taste-like properties by odors, there have been few reports of the acquisition of odor-like properties by taste (Prescott, 2012). In animals, some authors have demonstrated that taste input affects olfactory processing via a specialized "association" area (Desgranges et al., 2010). However, other works in conscious rats have shown that the gustatory system directly influences olfactory 
processing in the primary olfactory cortex (Maier et al., 2012). These results identify the posterior olfactory (piriform) cortex as a likely site for gustatory influences on olfactory processing.

We were surprised by the apparent lack of activation of the piriform cortex in the study by Castriota-Scanderbeg, in novices and experts, in neither the taste phase nor the after-taste phase (Castriota-Scanderbeg et al., 2005). Surprisingly, we found a similar absence in our study. However, as the threshold we used was maybe too strict; to enhance the piriform cortex we performed a ROI analysis centered on it. At a low threshold an activation is observed in the right piriform cortex for the contrast wine minus water for all subjects during the after-taste phase. Peak is obtained at $25,9,-14$ (Talairach coordinates), $t=2.24, p=$ 0.037 . A cluster size of 11 voxels of $1 \mathrm{~mm}^{3}$ is observed when the threshold is set at $p=0.05$ (uncorrected), and a cluster size of 2 voxels of $1 \mathrm{~mm}^{3}$ at $p=0.04$ (uncorrected). With such a small activated volume combined with such a poor statistic, we could consider that there is no activation of the piriform cortex in our study.

The piriform cortex is a small structure in humans and its proximity to the insular lobe may render identification of activations in this area difficult. This area corresponds to the retro-nasal olfactory process mainly during the after-taste phase. Although animal studies have identified the posterior olfactory (piriform) cortex as a likely site for gustatory influences on olfactory processing (Maier et al., 2012), the piriform cortex may respond preferentially to orthonasal odors, reflecting its role in olfaction, enhanced by sniffing (Zatorre et al., 1992; Sobel et al., 1998). Piriform activation by an odorant stimulus administered in solution form into the mouth (retronasal olfactory pathway) was found inconsistently in the literature (Small and Prescott, 2005). The reference study by Cerf-Ducastel and Murphy (2001) showed activation of right piriform cortex in the group analysis of the 6 involved subjects, but there was inconstancy at an individual level with activation of the left piriform in one subject, the right piriform in another, and both sides for a third subject, i.e., in less than half of the sample, and activations were found only with one stimulant (citral) among four. Some authors discuss in detail the inconstancy of the activation of this region in neuroimaging studies of olfaction (Small and Prescott, 2005). The inconstancy of activation of primary olfactory structures could be due to many reasons including the anatomical variability of the inferior frontal and lateral temporal areas, technical conditions, type of stimulus used (odorant in aqueous solution), the single retronasal pathway and the short process with adaptation and/or habituation effects. In addition, the initial amplitude of the activation decreases from block to block when using a block paradigm (Sobel et al., 2003). In this way, our results were similar with previous studies that showed that the piriform cortex would not be activated during the taste and flavor integration phase (Small et al., 1997; O'Doherty et al., 2001). This result could also be explained by the results of Small and Prescott (2005) who demonstrated differential neural recruitment depending on the route of odorant administration (ortho or retronasally) and by some behavioral experiments exploring the extent to which the aroma or non-volatile fractions are responsible for the overall flavor differences of wines perceived in-mouth (Sáenz-Navajas et al.,
2012; Villamor and Ross, 2013). A study performed under three different conditions (nose-close, retronasal perception only and retro- and orthonasal perception) have clearly shown that, globally, aroma perception is not the major driver of in-mouth sensory perception of red wine, which is undoubtedly primarily driven by the perception of astringency (Sáenz-Navajas et al., 2012). So we can attribute the absence of piriform activation mostly to the technical condition of supine administration of a small bolus of odorant in solution via a tube in mouth by shunting the orthonasal pathway. Perhaps wine experts can dissociate in the brain the three classical assessments of a wine (sight, orthonasal olfaction and then in-mouth sensations) before they make a synthesis.

\section{After-taste phase and flavor integration}

Firstly, our results in all subjects (experts and controls), showed activations in the insula, the operculum and the orbito-frontal cortex (Figure 1), which are all involved in taste/odor integration (Small et al., 1997, 2007; Rolls, 2008; Bender et al., 2009) as the key nodes of the "flavor network" (Small and Prescott, 2005). These regions represent the primary, secondary, and tertiary gustatory areas, and secondary and tertiary olfactory areas of the brain. Nevertheless, the piriform cortex was not activated during after-taste phase in our study, nor in the study by Castriota-Scanderbeg.

Common activations during the after-taste phase that are observed in both studies are the greater involvement of the

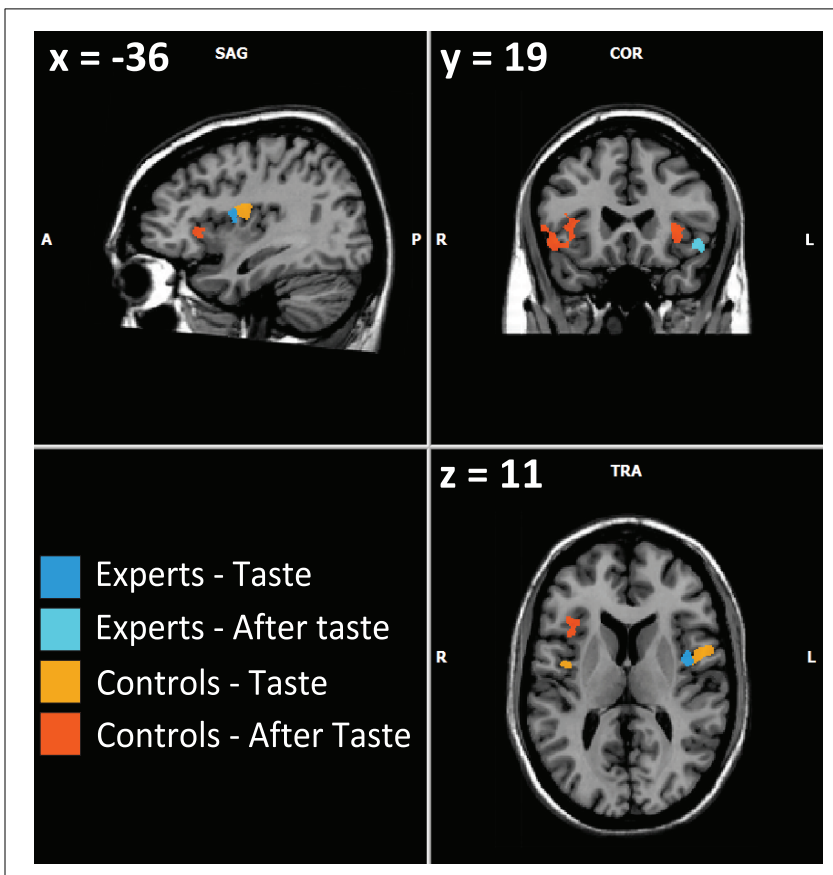

FIGURE 1 | Example of activations involving flavor integration (from Table 2). Visible activations are left pars opercularis and left and right insula for controls during the taste phase, right and left anterior insula and right orbitofrontal cortex for controls during the after-taste phase, left insula for experts during the taste phase, orbitofrontal cortex and the associative occipital cortex for experts during the after-taste phase. 
right side in the control group while bilateral and especially left frontal activation can be observed in the expert group. This suggests that our paradigm is effective in exploring expertise of flavor integration. Castriota-Scanderbeg et al. (2005) found in sommeliers a higher activation in the anterior insular, which is presumed to be involved in the integration of olfaction and gustation, as well as in the LPFC areas. In our study, experts were mainly characterized by recruitment of the hippocampal formation, regions of the temporal lobe and associative visual cortex. This could be explained by the persistence of memory processes. Neither the dorsolateral prefrontal cortex nor the orbito-frontal or anterior insular cortices were recruited during the after-taste phase in experts, as was the case in the study by Castriota-Scanderbeg et al. (2005). In their study, the integration of sensory processes appeared to continue during the after-taste period whereas, in our study, only memory structures persisted during the second phase. This difference between the two studies may be explained by the methodological designs, particularly the use of glucose as a reference stimulus.

Control subjects showed predominant activations in the right hemisphere. Temporal activations were more numerous than in the previous phase but no hippocampal or parahippocampal activations were observed. Frontal, parietal and occipital regions were involved to a lesser degree than previously and may have corresponded to the persistence of ineffective retrieval strategies. In control subjects, the anterior insula was only activated in the after-taste phase, whereas in experts, sensory integrationrelated regions were no longer activated during this phase.
This result indicates that experts showed a more immediate and targeted sensory reaction to wine stimulation than control subjects (Figure 2).

Olfactory and gustatory pathways appeared to be reciprocally connected. Asymmetrical involvement of the gustatory and olfactory regions in flavor processing is also supported by perceptual experiences and neuroimaging studies of taste/odor integration. The "flavor network" model involves multisensory integration, and the system can be subsequently engaged by unimodal stimulation (Prescott, 2012; Small, 2012).

Finally, it is proposed that there is asymmetric contribution of olfaction and gustation to flavor, such that only retronasally perceived odors (via the mouth) and odors previously experienced with taste (irrespective of mode of delivery) engage the flavor system (Prescott, 2012). To improve the understanding of the expertise on wine flavor integration, further studies should take into account the three phases of wine tasting, and neuroimaging protocol design should integrate the sight of wine, then orthonasal stimulation and finally in-mouth sensations. Our protocol, as well as Castriota-Scanderbeg's study, could be too restrictive, and this could explain the lack of important activations such as the piriform cortex activations.

However, and despite limitations of our study, our results are compatible with clear evidence for the overlapping and integration of gustatory, tactile and olfactory inputs in the insular cortex (Small, 2012). The core flavor percept is then conveyed to upstream regions in the brainstem and thalamus, as well as downstream regions in the amygdala, orbitofrontal cortex and

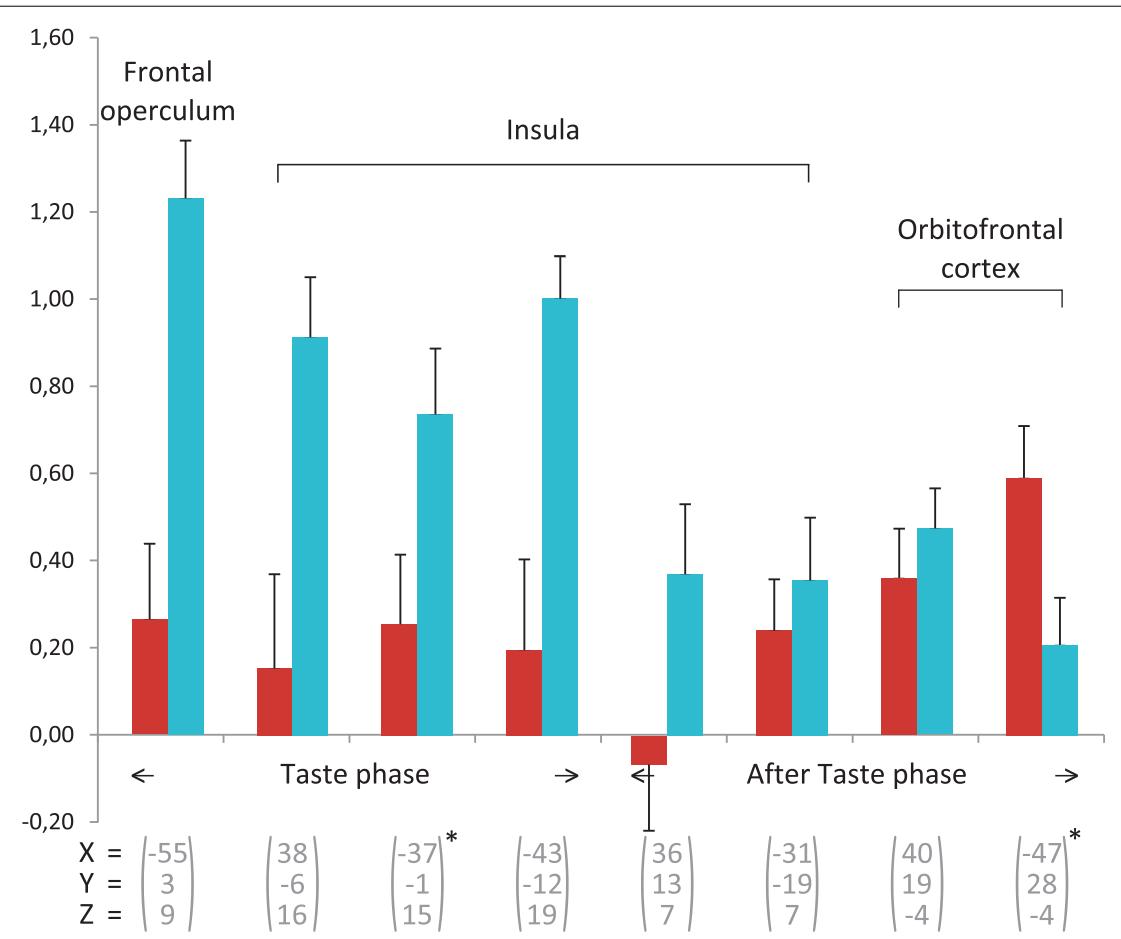

FIGURE 2 | Beta-value averages for the areas involved in flavor, based on Table 2. For each area from a group, the average values are given for the experts Group (red) and the Controls group (blue). The error bars indicate standard error. All regions of interest are from the Controls group, except for the two marked with * which are taken from the experts. 
anterior cingulate cortex to produce the rich flavorful experiences that guide our feeding behavior (Small, 2012).

\section{PARTICIPATION OF VARIOUS MEMORIES}

Although olfaction is the least easily categorizable and recognizable sensory modality (Richardson and Zucco, 1989), sommeliers have the unique ability to verbalize descriptors with all their senses. Sensory perceptions enable experts to provide an analytical description by referring to a large corpus of previously memorized and categorized data (Vedel et al., 1972), while novices cannot find the vocabulary to describe their olfactory and gustatory sensations.

Experts, but not novices, can write descriptions that they themselves or other experts can later match to the appropriate samples (Lawless, 1984; Solomon, 1990). A lot of behavioral studies tend to attribute the greater ability of wine experts to recognize and identify wine-relevant odorants to better semantic knowledge (Parr et al., 2002; D'Alessandro and Pecotich, 2013), and authors suggest that wine expertise may be more cognitive, rather than perceptual, expertise (Ballester et al., 2008). These mechanisms in wine experts might imply a predominance of the left hemisphere involved in analytic and linguistic treatment and probably the temporal lobes and hippocampus involved in episodic and semantic memory related to previous experiences. Other studies suggest the importance of perceptual skill, namely sensory memory for odorant and trigeminal perception, rather than semantic memory ability, in wine-relevant olfactory expertise (Parr et al., 2004).

In our study, numerous activations were observed in areas involved in memory processes, predominantly in the left hemisphere (Figures 3, 4). Hippocampal and parahippocampal activations were observed during retrieval tasks eliciting episodic or autobiographic memory or familiarity (Stark and Squire, 2001; Spaniol et al., 2009). Activity in the anterior temporal lobe corresponds to semantic memory (Rogers et al., 2006; Visser et al., 2010a,b) and left side involvement may particularly characterize the verbal knowledge used by experts when describing and labeling the wine in the recognition task.

Bilateral activation of the occipital cortex (associative area) may also have been related to mental imagery. Activations of the occipital gyri were also noted by Royet et al. (1999) in judgments of edibility of different odorants.

In some professional activities and hobbies, tasks requiring expertise are supported by specific sensory and cognitive skills. Cerebral imaging studies have provided insight into the adaptive cerebral networks underlying these abilities. With expertise, an "economic" mechanism may result in enhanced efficiency, reduced effort and increased spontaneity (Hund-Georgiadis and von Cramon, 1999; Maguire et al., 2000; Lotze et al., 2003; Plailly et al., 2012). Accordingly, during the after-taste phase, fewer activations are observed in experts vs. novices and mainly in episodic and semantic memory network (temporal pole, hippocampus and parahippocampal gyrus) and mental imaging (occipital associative area) suggesting that experts classify and compare this sensorial stimulus with their own episodic experience and semantic knowledge. The comparison of control minus expert did not show specific activation of the olfactory or gustatory structures

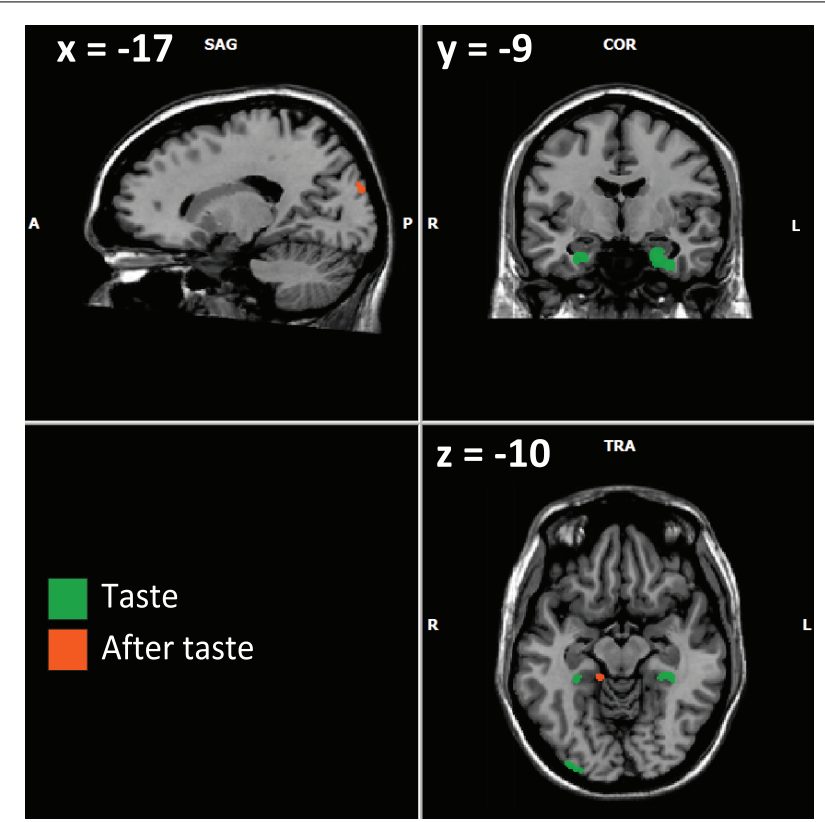

FIGURE 3 | Example of activations involving memory (from Table 3) for the contrast experts minus controls. Activations in green are obtained during the taste phase; those in orange are obtained during the after-taste phase. Visible activations are both in the amygdala/hippocampus complex (taste phase), parahippocampal gyri (right and left for the taste phase, right for the after-taste phase), occipital associative cortex (right during the taste phase, left during the after-taste phase).

during taste phase and then only insula during the after-taste phase suggests a slower and incomplete analysis of the stimulus. During the after-taste phase diffuse activation probably suggests an ineffective retrieval strategy for the novice. For the novice, the treatment requires deeper thinking and passes very quickly to a high level in the cortical areas of the brain, using a much more diffuse and therefore less specific network. Unable to recognize or recall experts' knowledge, they quickly use their episodic memory (Tulving, 1995). They try to associate taste and perceived memories of places and people, in order to contextualize and identify it, and associate it with emotion. From an information processing perspective, this would suggest that experts could have more attention (working memory capacity) to direct to the task at hand, unencumbered by the associated semantic and affective input (Parr et al., 2004).

The hypothesis on memory mechanisms involved in experience should be explored further by time-series analysis methods such as Dynamic Causal Modeling or Granger Causality Analysis (Seth et al., 2013) to better understand the dynamic and interaction of the different kind of memory during wine flavor analysis.

\section{ROLE OF EXPERTISE}

The perceived quality of a wine is dependent on consumers' level of expertise (Sáenz-Navajas et al., 2013). Wine tasting expertise involves advanced discriminative and descriptive abilities with respect to wine. Cortical and brainstem activations showed two different and complementary mechanisms of wine expertise: a 


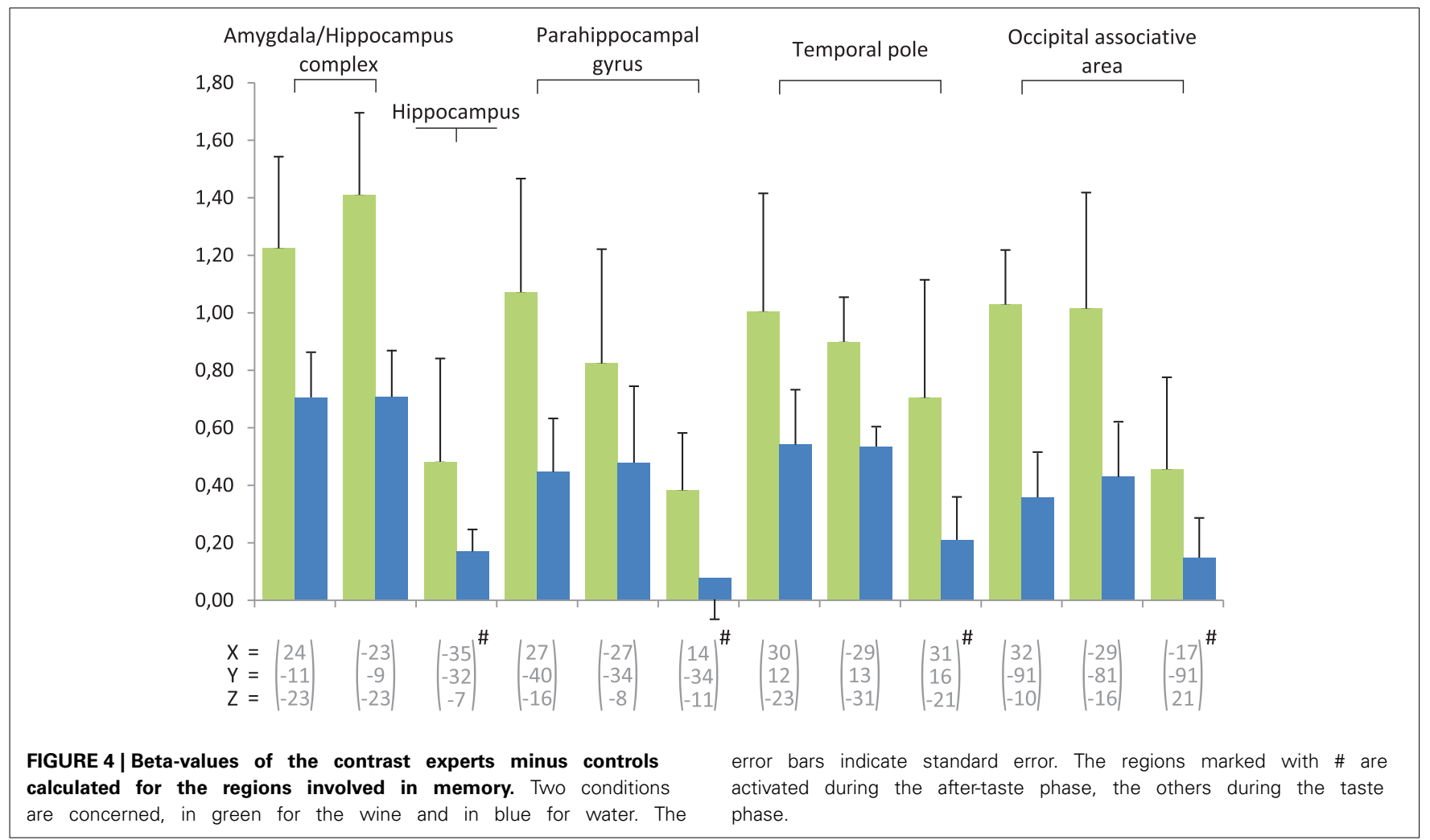

perceptive mechanism of modulation of the afferent input of information corresponding to the activated gustatory and trigeminal brainstem structures, and specialized cognitive analysis, with focalized cortical activations especially in the left structures involved in memory, language and chemosensory analysis.

A sommelier can distinguish a subtle difference of taste in wine by training their ability to integrate information from gustatory and olfactory senses with past experience.

During the wine tasting phase, control subjects showed fewer but larger activated regions than experts. In control subjects, these activations predominantly occurred in the right hemisphere, and were widespread in the parietal, occipital and frontal cortices. Frontal activations included the frontal operculum which is, like the above mentioned adjoining anterior insula, a putative primary taste cortex (Rolls and Scott, 2003; Pritchard and Norgren, 2004). It is also considered to be a secondary cortex related to odor memory (Savic, 2002). Right occipital activation including the associative visual cortex and parieto-occipital junction was found. Once again, we can hypothesize that this corresponds to mental imaging of past wine tasting experiences and of terms used to describe the taste of wine (fruity for example) or even its color (Qureshy et al., 2000). These associative visual areas were more activated in controls than in experts (in terms of cluster size). This could have been because most of this information corresponded to the experts' semantic knowledge (especially verbal), making them less likely to need to refer to visual images.

During after-taste phase, experts were mainly characterized by recruitment of the hippocampal formation, regions of the temporal lobe and associative visual cortex (Figure 4). This could be explained by the persistence of memory processes. Neither the dorsolateral prefrontal cortex nor the orbito-frontal or anterior insular cortices were recruited during the after-taste phase in experts, as was the case in the study by Castriota-Scanderbeg et al. (2005). In their study, the integration of sensory processes appeared to continue during the after-taste period whereas, in our study, only memory structures were persistent during the second phase. This difference between the two studies may be explained by the methodological designs, particularly the use of glucose as a reference stimulus. Control subjects showed predominant activations in the right hemisphere. Temporal activations were more numerous than in the previous phase but no hippocampal or parahippocampal activations were observed. Frontal, parietal and occipital regions were involved to a lesser degree than previously, but again this widespread recruitment of cerebral areas might correspond to the persistence of ineffective retrieval strategies. In control subjects, the anterior insula was only activated in the after-taste phase, whereas in experts, sensory integrationrelated regions were no longer activated during this phase. This result indicates that experts showed a more immediate and targeted sensory reaction to wine stimulation than control subjects. This analysis delay in the control subjects is a logical consequence of their level of expertise. Similarly, Plailly et al. (2012) demonstrated that the right anterior insula is more activated in students than in professionals in perfumery during odor imagery tasks.

\section{EXTERNAL VALUE FOR OTHER ALCOHOLIC BEVERAGES}

The discrepancy of our results with the previous ones from Castriota-Scanderbeg raise questions about the role of expertise during the initial taste phase which should be explored by further studies using a direct comparison between water, glucose 
solution, salty solution, sweet wine and dry wine to improve the understanding of the expertise of flavor integration and the modification induced by those factors. Otherwise, one might think that our results are largely generalizable to different test situations of alcoholic beverages comparing experts and novices. The involvement of brain structures involved in memory is indeed expected in experts regardless of the type of beverage, as well as the participation of different associative cortical areas in novice subjects. However, the specific compounds and sensory qualities of wine can marginally change significant differences (Villamor and Ross, 2013). The technical conditions of taste (taste phase) and olfaction (after-taste phase) may have some effects (Sáenz-Navajas et al., 2012) and because the same brain areas are not equally concerned whatever the flavor (sweet, bitter, sour) or aroma (Rolls et al., 2003; Small and Prescott, 2005), special attention should focus on different positive hedonic valence such as dry or sweet wine. Slightly different locations of the orbitofrontal cortex may be suspected in the case of strong bitterness such as beer relative to sweet flavors (Small et al., 2007). Trigeminal sensations during the test phase can however vary greatly (depending on alcohol content, tannin, astringency, $\mathrm{pH}$...) and therefore recruit more or less the secondary somatosensory cortex S II (Bensafi et al., 2008; Billot et al., 2011; King et al., 2013).

\section{CONCLUSION}

This study describes the differences in brain activity of sommeliers compared to "naive" subjects during a blind taste test of wine samples as stimuli relative to water, in order to confirm the influence of expertise on the integration of flavor.

The present study was based on different stimuli compared to the only previous study with sommeliers and used a tasteless reference. Expertise impacts basic taste processing, and when comparing expert minus control, during the taste phase, early sensorial and hedonic structures (trigeminal nucleus, amygdala, insula) and familiarity structures (parahippocampal gyrus) are activated suggesting early analysis of the stimulus. Interestingly, brain stem responses have been observed in experts during this taste phase. During the after-taste phase, the experts showed greater activation in the left orbitofrontal cortex, left insular cortex and dorsolateral prefrontal cortex. Our results are consistent with previous studies, particularly in terms of the lateralization of the expertise-related process (predominantly restricted to the left hemisphere in experts). As suggested, the leftward specialization occurs at the expense of normal rightward activity.

Our study also revealed more involvement in experts of hippocampal, parahippocampal, anterior temporal regions and associative occipital area associated with different types of memory, suggesting that wine experts probably process by similitude to try to recognize all characteristics (country origin, cepage, "appellation," millesime) of the wine, and further analyses such as Dynamic Causal Modeling or Granger Causality Analysis are needed to deeply understand the chronological functioning of brain networks of wine experts.

More generally, our results indicate that wine experts showed a more immediate and targeted sensory reaction to wine stimulation than control subjects. The influence of expertise on flavor integration may mainly comprise quicker sensorial integration with an economic mechanism reducing effort and increasing efficacy. Experts seem to also activate sensory memory and episodic memory as well as working memory and semantic memory. These results confirm that wine experts work simultaneously on sensory quality assessment and on label recognition of wine. To improve the understanding of the effect of expertise on wine flavor integration, further studies should take into account the three phases of wine tasting, and neuroimaging protocol design should integrate the sight of the wine, then orthonasal stimulation and finally in-mouth sensations.

\section{ACKNOWLEDGMENTS}

We would like to thank Holly Sandu (Medical and scientific translator) for her assistance in translating and proofreading our manuscript. We would like to thank Christophe Menozzi (2001, Maître Sommelier de France UDSF) for his contribution to the establishment of the experimental scheme and the choice of wines. We would like to thank the wine domains that provided the wine: Arbois 2004, Chardonnay "Les Brulées" Domaine St Pierre, Mathenay, FR; Côte du Jura 2006, Pinot noir "Cuvée dédicacée," Benoît Badoz, Poligny, FR. We wish to give special thanks to the "Conseil Regional de Franche-Comte" for its financial support allowing the use of the MR-3T Scanner for this research.

\section{REFERENCES}

Andrieu, P., Bonnans, V., Meneses, J., Millot, J. L., Moulin, T., and Gharbi, T. (2014). A modular, computer-controlled system for olfactory stimulation in the MRI environment. Behav. Res. Methods 46, 178-184. doi: 10.3758/s13428-0130362-x

Auvray, M., and Spence, C. (2008). The multisensory perception of flavor. Conscious. Cogn. 17, 1016-1031. doi: 10.1016/j.concog.2007.06.005

Ballester, J., Patris, B., Symoneaux, R., and Valentin, D. (2008). Conceptual vs. perceptual wine spaces: does expertise matter? Food Qual. Prefer. 19, 267-276. doi: 10.1016/j.foodqual.2007.08.001

Bender, G., Veldhuizen, M. G., Meltzer, J. A., Gitelman, D. R., and Small, D. M. (2009). Neural correlates of evaluative compared with passive tasting. Eur. J. Neurosci. 30, 327-338. doi: 10.1111/j.1460-9568.2009.06819.x

Bengtsson, S., Berglund, H., Gulyas, B., Cohen, E., and Savic, I. (2001). Brain activation during odor perception in males and females. Neuroreport 12, 2027-2033. doi: 10.1097/00001756-200107030-00048

Bensafi, M., Croy, I., Phillips, N., Rouby, C., Sezille, C., Gerber, J., et al. (2014). The effect of verbal context on olfactory neural responses. Hum. Brain Mapp. 35, 810-818. doi: 10.1002/hbm.22215

Bensafi, M., Iannilli, E., Gerber, J., and Hummel, T. (2008). Neural coding of stimulus concentration in the human olfactory and trigeminal systems. Neuroscience 154, 832-838. doi: 10.1016/j.neuroscience.2008.03.079

Billot, P. E., Comte, A., Galliot, E., Andrieu, P., Bonnans, V., Tatu, L., et al. (2011). Time course of odorant- and trigeminal-induced activation in the human brain: an event-related functional magnetic resonance imaging study. Neuroscience 189, 370-376. doi: 10.1016/j.neuroscience.2011.05.035

Blackman, J., Saliba, A., and Schmidtke, L. (2010). Sweetness acceptance of novices, experienced consumers and winemakers in Hunter Valley Semillon wines. Food Qual. Prefer. 21, 679-683. doi: 10.1016/j.foodqual.2010.05.001

Boyle, J. A., Frasnelli, J., Gerber, J., Heinke, M., and Hummel, T. (2007a). Cross-modal integration of intranasal stimuli: a functional magnetic resonance imaging study. Neuroscience 149, 223-231. doi: 10.1016/j.neuroscience.2007. 06.045

Boyle, J. A., Heinke, M., Gerber, J., Frasnelli, J., and Hummel, T. (2007b). Cerebral activation to intranasal chemosensory trigeminal stimulation. Chem. Senses 32, 343-353. doi: 10.1093/chemse/bjm004

Boynton, G. M., Engel, S. A., Glover, G. H., and Heeger, D. J. (1996). Linear systems analysis of functional magnetic resonance imaging in human V1. J. Neurosci. 16 , 4207-4221. 
Brand, G., and Brisson, R. (2012). Lateralisation in wine olfactory threshold detection: comparison between experts and novices. Laterality 17, 583-596. doi: 10.1080/1357650X.2011.595955

Brand, G., and Millot, J. L. (2001). Sex differences in human olfaction: between evidence and enigma. Q. J. Exp. Psychol. B. 54, 259-270. doi: 10.1080/02724990143000045

Brochet, F., and Dubourdieu, D. (2001). Wine descriptive language supports cognitive specificity of chemical senses. Brain Lang. 77, 187-196. doi: 10.1006/brln.2000.2428

Burdach, K. J., and Doty, R. L. (1987). The effects of mouth movements, swallowing, and spitting on retronasal odor perception. Physzol. Behav. 41, 353-356. doi: 10.1016/0031-9384(87)90400-8

Castriota-Scanderbeg, A., Hagberg, G. E., Cerasa, A., Committeri, G., Galati, G., Patria, F., et al. (2005). The appreciation of wine by sommeliers: a functional magnetic resonance study of sensory integration. Neuroimage 25, 570-578. doi: 10.1016/j.neuroimage.2004.11.045

Cerf-Ducastel, B., and Murphy, C. (2001). fMRI activation in response to odorants orally delivered in aqueous solutions. Chem. Senses 26, 625-637. doi: $10.1093 /$ chemse/26.6.625

D'Alessandro, S., and Pecotich, A. (2013). Evaluation of wine by expert and novice consumers in the presence of variations in quality, brand and country of origin cues. Food Qual. Prefer. 28, 28-303.

de Araujo, I. E., Rolls, E. T., Kringelbach, M. L., McGlone, F., and Phillips, N. (2003). Taste-olfactory convergence, and the representation of the pleasantness of flavour, in the human brain. Eur. J. Neurosci. 18, 2059-2068. doi: 10.1046/j.1460-9568.2003.02915.x

Desgranges, B., Ramirez-Amaya, V., Ricano-Cornejo, I., Levy, F., and Ferreira, G. (2010). Flavor preference learning increases olfactory and gustatory convergence onto single neurons in the basolateral amygdala but not in the insular cortex in rats. PLoS ONE 5:e10097. doi: 10.1371/journal.pone.0010097

Doty, R. L. (1989). Influence of age and age-related diseases on olfactory function. Ann. N.Y. Acad. Sci. 561, 76-86. doi: 10.1111/j.1749-6632.1989.tb 20971.x

Francis, S., Rolls, E. T., Bowtell, R., McGlone, F., O’Doherty, J., Browning, A., et al. (1999). The representation of pleasant touch in the brain and its relationship with taste and olfactory areas. Neuroreport 10, 453-459.

Fu, W., Sugai, T., Yoshimura, H., and Onoda, N. (2004). Convergence of olfactory and gustatory connections onto the endopiriform nucleus in the rat. Neuroscience 126, 1033-1041. doi: 10.1016/j.neuroscience.2004.03.041

Fulbright, R. K., Skudlarski, P., Lacadie, C. M., Warrenburg, S., Bowers, A. A., Gore, J. C., et al. (1998). Functional MR imaging of regional brain responses to pleasant and unpleasant odors. AJNR Am. J. Neuroradiol. 19, 1721-1726.

González, J., Barros-Loscertales, A., Pulvermuller, F., Meseguer, V., Sanjuan, A., Belloch, V., et al. (2006). Reading cinnamon activates olfactory brain regions Neuroimage 32, 906-912. doi: 10.1016/j.neuroimage.2006.03.037

Haase, L., Cerf-Ducastel, B., and Murphy, C. (2009). The effect of stimulus delivery technique on perceived intensity functions for taste stimuli: implications for fMRI studies. Atten. Percept. Psychophys. 71, 1167-1173. doi: 10.3758/APP.71.5.1167

Hughson, A. L., and Boakes, R. A. (2002). The knowing nose: the role of knowledge in wine expertise. Food Qual. Prefer. 13, 463-472. doi: 10.1016/S09503293(02)00051-4

Hund-Georgiadis, M., and von Cramon, D. Y. (1999). Motor-learning-related changes in piano players and non-musicians revealed by functional magneticresonance signals. Exp. Brain Res. 125, 417-425. doi: 10.1007/s002210050698

Katotomichelakis, M., Balatsouras, D., Tripsianis, G., Davris, S., Maroudias, N., Danielides, V., et al. (2007). The effect of smoking on the olfactory function. Rhinology 45, 273-280.

Kikuchi, S., Kubota, F., Nisijima, K., Washiya, S., and Kato, S. (2005). Cerebral activation focusing on strong tasting food: a functional magnetic resonance imaging study. Neuroreport 16, 281-283. doi: 10.1097/00001756-20050228000016

King, E. S., Dunn, R. L., and Heymann, H. (2013). The influence of alcohol on the sensory perception of red wines. Food Qual. Prefer. 28, 235-243. doi: 10.1016/j.foodqual.2012.08.013

Kinomura, S., Kawashima, R., Yamada, K., Ono, S., Itoh, M., Yoshioka, S., et al. (1994). Functional anatomy of taste perception in the human brain studied with positron emission tomography. Brain Res. 659, 263-266. doi: 10.1016/00068993(94)90890-7
Kobayashi, M. (2006). Functional organization of the human gustatory cortex. J. Oral Biosci. 48, 244-260. doi: 10.1016/S1349-0079(06)80007-1

Kobayashi, M., Takeda, M., Hattori, N., Fukunaga, M., Sasabe, T., Inoue, N., et al. (2004). Functional imaging of gustatory perception and imagery: “top-down" processing of gustatory signals. Neuroimage 23, 1271-1282. doi: 10.1016/j.neuroimage.2004.08.002

Kühn, S., and Gallinat, J. (2013). Does taste matter? How anticipation of cola brands influences gustatory processing in the brain. PLOS ONE 8:e61569. doi: 10.1371/journal.pone.0061569

Laska, M., Distel, H., and Hudson, R. (1997). Trigeminal perception of odorant quality in congenitally anosmic subjects. Chem. Senses 22, 447-456. doi: 10.1093/chemse/22.4.447

Lawless, H. T. (1984). Flavor description of white wine by "expert" and nonexpert wine consumers. J. Food Sci. 49, 120-123. doi: 10.1111/j.1365-2621.1984. tb13686.x

Lombion, S., Comte, A., Tatu, L., Brand, G., Moulin, T., and Millot, J. L. (2009). Patterns of cerebral activation during olfactory and trigeminal stimulations. Hum. Brain Mapp. 30, 821-828. doi: 10.1002/hbm.20548

Lotze, M., Scheler, G., Tan, H. R., Braun, C., and Birbaumer, N. (2003) The musician's brain: functional imaging of amateurs and professionals during performance and imagery. Neuroimage 20, 1817-1829. doi: 10.1016/j.neuroimage.2003.07.018

Lundstrom, J. N., and Hummel, T. (2006). Sex-specific hemispheric differences in cortical activation to a bimodal odor. Behav. Brain Res. 166, 197-203. doi: 10.1016/j.bbr.2005.07.015

Maguire, E. A., Gadian, D. G., Johnsrude, I. S., Good, C. D., Ashburner, J., Frackowiak, R. S., et al. (2000). Navigation-related structural change in the hippocampi of taxi drivers. Proc. Natl. Acad. Sci. U.S.A. 97, 4398-4403. doi: 10.1073/pnas.070039597

Maier, J. X., Wachowiak, M., and Katz, D. B. (2012). Chemosensory convergence on primary olfactory cortex. J. Neurosci. 32, 17037-17047. doi 10.1523/JNEUROSCI.3540-12.2012

McClure, S. M., Li, J., Tomlin, D., Cypert, K. S., Montague, L. M., and Montague, P. R. (2004). Neural correlates of behavioral preference for culturally familiar drinks. Neuron 44, 379-387. doi: 10.1016/j.neuron.2004.09.019

Morrot, G., Brochet, F., and Dubourdieu, D. (2001). The color of odors. Brain Lang. 79, 309-320. doi: 10.1006/brln.2001.2493

O'Doherty, J., Rolls, E. T., Francis, S., Bowtell, R., and McGlone, F. (2001). Representation of pleasant and aversive taste in the human brain. J. Neurophysiol. 85, 1315-1321. doi: 10.1.1.23.1477

Okamoto, M., and Dan, I. (2013). Extrinsic information influences taste and flavor perception: a review from psychological and neuroimaging perspectives. Semin. Cell Dev. Biol. 24, 247-255. doi: 10.1016/j.semcdb.2012. 11.001

Parr, W. V., Heatherbell, D., and White, K. G. (2002). Demystifying wine expertise: olfactory threshold, perceptual skill and semantic memory in expert and novice wine judges. Chem. Senses 27, 747-755. doi: 10.1093/chemse/ 27.8.747

Parr, W. V., White, K. G., Heatherbell, D. A. (2004). Exploring the nature of wine expertise: what underlies wine experts' olfactory recognition memory advantage? Food Qual. Prefer. 15, 411-420. doi: 10.1016/j.foodqual.2003.07.002

Pierce, J., and Halpern, B. (1996). Orthonasal and retronasal odorant identification based upon vapor phase input from common sub-stances. Chem. Senses 21, 529-543. doi: 10.1093/chemse/21.5.529

Plailly, J., Delon-Martin, C., and Royet, J. P. (2012). Experience induces functional reorganization in brain regions involved in odor imagery in perfumers. Hum. Brain Mapp. 33, 224-234. doi: 10.1002/hbm.21207

Plassmann, H., O’Doherty, J., Shiv, B., and Rangel, A. (2008). Marketing actions can modulate neural representations of experienced pleasantness. Proc. Natl. Acad. Sci. U.S.A. 105, 1050-1054. doi: 10.1073/pnas.0706929105

Prescott, J. (1999). Flavor as a psychological construct: implications for perceiving and measuring the sensory qualities of foods. Food Qual. Prefer. 10, 349-356. doi: 10.1016/S0950-3293(98)00048-2

Prescott, J. (2012). "Multimodal chemosensory interactions and perception of flavour," in The Neural Bases of Multisensory Processes, eds M. M. Murray and M. T. Wallace (Boca Raton, FL: CRC Press), Chap 35.

Pritchard, T. C., and Norgren, R. (2004). "Gustatory system," in The Human Nervous System, eds G. Paxinos and J. K. Mai (Amsterdam: Elsevier), 1171-1196. doi: 10.1016/B978-012547626-3/50032-6 
Qureshy, A., Kawashima, R., Imran, M. B., Sugiura, M., Goto, R., Okada, K., et al. (2000). Functional mapping of human brain in olfactory processing: a PET study. J. Neurophysiol. 84, 1656-1666.

Richardson, J. T., and Zucco, G. M. (1989). Cognition and olfaction: a review. Psychol. Bull. 105, 352-360. doi: 10.1037/0033-2909.105.3.352

Rogers, T. T., Hocking, J., Noppeney, U., Mechelli, A., Gorno-Tempini, M. L., Patterson, K., et al. (2006). Anterior temporal cortex and semantic memory: reconciling findings from neuropsychology and functional imaging. Cogn. Affect. Behav. Neurosci. 6, 201-213. doi: 10.3758/CABN.6.3.201

Rolls, E. T., and Scott, T. (2003). "Central taste anatomy and neurophysiology," in Handbook of Olfaction and Gustation, ed R. L. Doty (New York, NY: Marcel Dekker), 679-705.

Rolls, E. T. (2008). Functions of the orbitofrontal and pregenual cingulate cortex in taste, olfaction, appetite and emotion. Acta Physiol. Hung. 95, 131-164. doi: 10.1556/APhysiol.95.2008.2.1

Rolls, E. T., Kringelbach, M. L., and de Araujo, I. E. T. (2003). Different representations of pleasant and unpleasant odours in the human brain. Eur. J. Neurosci. 18, 695-703. doi: 10.1046/j.1460-9568.2003.02779.x

Royet, J. P., Delon-Martin, C., and Plailly, J. (2013a). Odor mental imagery in non-experts in odors: a paradox? Front. Hum. Neurosci. 7:87. doi: 10.3389/fnhum.2013.00087

Royet, J. P., Koenig, O., Gregoire, M. C., Cinotti, L., Lavenne, F., Le Bars, D., et al. (1999). Functional anatomy of perceptual and semantic processing for odors. J. Cogn. Neurosci. 11, 94-109. doi: 10.1162/089892999563166

Royet, J. P., Plailly, J., Saive, A. L., Veyrac, A., and Delon-Martin, C. (2013b). The impact of expertise in olfaction. Front Psychol. 4:928. doi: 10.3389/fpsyg.2013.00928

Rozin, P. (1982). "Taste-smell confusions" and the duality of the olfactory sense. Percept. Psychophys. 31, 397-401. doi: 10.3758/BF03202667

Sáenz-Navajas, M. P., Ballester, J., Pêcher, C., Peyron, D., and Valentin, D. (2013). Sensory drivers of intrinsic quality of red wines: effect of culture and level of expertise. Food Res. Int. 54, 1506-1518. doi: 10.1016/j.foodres.2013. 09.048

Sáenz-Navajas, M. P., Campo, E., Avizcuri, J. M., Valentin, D., FernándezZurbano, P., and Ferreira, V. (2012). Contribution of non-volatile and aroma fractions to in-mouth sensory properties of red wines: wine reconstitution strategies and sensory sorting task. Anal. Chim. Acta. 732, 64-72. doi: 10.1016/j.aca.2011.12.042

Saive, A. L., Royet, J. P., and Plailly, J. (2014). A review on the neural bases of episodic odor memory: from laboratory-based to autobiographical approaches. Front. Behav. Neurosci. 8:240. doi: 10.3389/fnbeh.2014.00240

Salles, C., Chagnon, M. C., Feron, G., Guichard, E., Laboure, H., Morzel, M., et al. (2011). In-mouth mechanisms leading to flavor release and perception. Crit. Rev. Food Sci. Nutr. 51, 67-90. doi: 10.1080/10408390903044693

Savic, I. (2002). Brain imaging studies of the functional organization of human olfaction. Neuroscientist 8, 204-211. doi: 10.1177/1073858402008003006

Seth, A. K., Chorley, P., and Barnett, L. C. (2013). Granger causality analysis of fMRI BOLD signals is invariant to hemodynamic convolution but not downsampling. Neuroimage 65, 540-555. doi: 10.1016/j.neuroimage.2012.09.049

Small, D. M. (2012). Flavor is in the brain. Physiol. Behav. 107, 540-552. doi: 10. 1016/j.physbeh.2012.04.011

Small, D. M., Bender, G., Veldhuizen, M. G., Rudenga, K., Nachtigal, D., and Felsted, J. (2007). The role of the human orbitofrontal cortex in taste and flavor processing. Ann. N.Y. Acad. Sci. 1121, 136-151. doi: 10.1196/annals. 1401.002

Small, D. M., Jones-Gotman, M., Zatorre, R. J., Petrides, M., and Evans, A. C. (1997). Flavor processing: more than the sum of its parts. Neuroreport 8, 3913-3917. doi: 10.1097/00001756-199712220-00014

Small, D. M., and Prescott, J. (2005). Odor/taste integration and the perception of flavor. Exp. Brain Res. 166, 345-357. doi: 10.1007/s00221-005-2376-9

Small, D. M., Voss, J., Mak, Y. E., Simmons, K. B., Parrish, T., and Gitelman, D. (2004). Experience-dependent neural integration of taste and smell in the human brain. J. Neurophysiol. 92, 1892-1903. doi: 10.1152/jn.00050.2004

Small, D. M., Zald, D. H., Jones-Gotman, M., Zatorre, R. J., Pardo, J. V., Frey, S., et al. (1999). Human cortical gustatory areas: a review of functional neuroimaging data. Neuroreport 10, 7-14. doi: 10.1097/00001756-19990118000002

Small, D. M., Zatorre, R. J., Dagher, A., Evans, A. C., and Jones-Gotman, M. (2001). Changes in brain activity related to eating chocolate: from pleasure to aversion. Brain 124, 1720-1733. doi: 10.1093/brain/124.9.1720
Sobel, N., Bradley, N. J., Mainland, J., and Yousem, D. M. (2003). "Functional neuroimaging of human olfaction," in Handbook of Olfaction and Gustation, ed R. L. Doty (New York, NY: Marcel Dekker), 251-273.

Sobel, N., Prabhakaran, V., Desmond, J. E., Glover, G. H., Goode, R. L., Sullivan, E. V., et al. (1998). Sniffing and smelling: separate subsystems in the human olfactory cortex. Nature 392, 282-286. doi: 10.1038/32654

Solomon, G. (1990). Psychology of novice and expert wine talk. Am. J. Psychol. 105, 495-517. doi: 10.2307/1423321

Spaniol, J., Davidson, P. S., Kim, A. S., Han, H., Moscovitch, M., and Grady, C. L. (2009). Event-related fMRI studies of episodic encoding and retrieval: meta-analyses using activation likelihood estimation. Neuropsychologia 47, 1765-1779. doi: 10.1016/j.neuropsychologia.2009.02.028

Stark, C. E., and Squire, L. R. (2001). Simple and associative recognition memory in the hippocampal region. Learn. Mem. 8, 190-197. doi: 10.1101/lm.40701

Talairach, J., and Tournoux, P. (1988). Co-Planar Stereotaxic Atlas of the Human Brain: 3-Dimensional Proportional System: An Approach to Cerebral Imaging. New York, NY: Thieme Medical Publishers.

Tulving, E. (1995). "Organisation of memory: quo vadis?" in The Cognitive Neurosciences, ed M. S. Gazzaniga (Cambridge, MA: MIT Press), 839-847.

Van den Bosch, I., Dalenberg, J. R., Renken, R., Van Langeveld, A. W., Smeets, P. A., Griffioen-Roose, S., et al. (2014). To like or not to like: neural substrates of subjective flavor preferences. Behav. Brain Res. 269, 128-137. doi: 10.1016/j.bbr.2014.04.010

Vedel, A., Charle, G., Charnay, P., and Tourmeau, J. (1972). Essai sur la Dégustation des Vins. Mâcon: Institut National des Appellations d'Origine des Vins et Eauxde-Vie.

Vicente, K. J., and Wang, J. H. (1998). An ecological theory of expertise effects in memory recall. Psychol. Rev. 105, 33-57. doi: 10.1037/0033-295X.105.1.33

Villamor, R. R., and Ross, C. F. (2013). Wine matrix compounds affect perception of wine aromas. Annu. Rev. Food Sci. Technol. 4, 1-20. doi: 10.1146/annurevfood-030212-182707

Visser, M., Embleton, K. V., Jefferies, E., Parker, G. J., and Ralph, M. A. (2010a). The inferior, anterior temporal lobes and semantic memory clarified: novel evidence from distortion-corrected fMRI. Neuropsychologia 48, 1689-1696. doi: 10.1016/j.neuropsychologia.2010.02.016

Visser, M., Jefferies, E., and Lambon Ralph, M. A. (2010b). Semantic processing in the anterior temporal lobes: a meta-analysis of the functional neuroimaging literature. J. Cogn. Neurosci. 22, 1083-1094. doi: 10.1162/jocn.2009. 21309

Wang, J., Eslinger, P. J., Smith, M. B., and Yang, Q. X. (2005). Functional magnetic resonance imaging study of human olfaction and normal aging. J. Gerontol. A Biol. Sci. Med. Sci. 60, 510-514. doi: 10.1093/gerona/60.4.510

Yousem, D. M., Maldjian, J. A., Siddiqi, F., Hummel, T., Alsop, D. C., Geckle, R. J., et al. (1999). Gender effects on odor-stimulated functional magnetic resonance imaging. Brain Res. 818, 480-487. doi: 10.1016/S0006-8993(98) 01276-1

Zald, D. H., and Pardo, J. V. (2000). Cortical activation induced by intraoral stimulation with water in humans. Chem. Senses 25, 267-275. doi: $10.1093 /$ chemse/25.3.267

Zatorre, R. J., Jones-Gotman, M., Evans, A. C., and Meyer, E. (1992). Functional localization and lateralization of human olfactory cortex. Nature 360, 339-340. doi: $10.1038 / 360339 \mathrm{a} 0$

Conflict of Interest Statement: The authors declare that the research was conducted in the absence of any commercial or financial relationships that could be construed as a potential conflict of interest.

Received: 30 July 2014; accepted: 26 September 2014; published online: 16 October 2014.

Citation: Pazart L, Comte A, Magnin E, Millot J-L and Moulin T (2014) An fMRI study on the influence of sommeliers' expertise on the integration of flavor. Front. Behav. Neurosci. 8:358. doi: 10.3389/fnbeh.2014.00358

This article was submitted to the journal Frontiers in Behavioral Neuroscience.

Copyright (C) 2014 Pazart, Comte, Magnin, Millot and Moulin. This is an openaccess article distributed under the terms of the Creative Commons Attribution License (CC BY). The use, distribution or reproduction in other forums is permitted, provided the original author(s) or licensor are credited and that the original publication in this journal is cited, in accordance with accepted academic practice. No use, distribution or reproduction is permitted which does not comply with these terms. 